\title{
Management of Hereditary Breast Cancer
}

\author{
D.M. Eccles ${ }^{1}$, P. Simmonds ${ }^{2}$, J. Goddard ${ }^{3}$, \\ M. Coultas ${ }^{1}$, F. Lalloo ${ }^{2}$, G. Evans ${ }^{2}$ \\ and N. Haites ${ }^{5}$ in collaboration with the \\ European Familial Breast Cancer \\ Collaborative Group \\ ${ }^{1}$ Department of Clinical Genetics, Princess \\ Ann Hospital, Coxford Road, Southampton, \\ UK \\ ${ }^{2}$ Medical Oncology, Royal South Hants \\ Hospital, Southampton, UK \\ ${ }^{3}$ Medical Statistics and Computing, \\ Southampton General Hospital, \\ Southampton, UK \\ ${ }^{4}$ Clinical Genetics, St. Mary's Hospital, \\ Manchester, UK \\ ${ }^{5}$ Department of Medical Genetics, Aberdeen \\ Royal Infirmary, Aberdeen, UK
}

Breast cancer treatment has changed a great deal over the course of the last century. From the old radical mastectomy with its attendant morbidity and mortality, through the recognition of hormonal manipulation as a useful treatment, the introduction of radiotherapy and the gradual move away from mutilating surgery to the current cosmetically and psychologically (for some) more appealing option of breast conserving treatment. Wide local excision and adjuvant radiotherapy is now a standard treatment option whenever this is technically possible and clinically likely to be of equivalent efficacy in terms of curing disease. Clinical trials show no difference in outlook for women treated with breast conserving treatment compared to women treated with conventional simple mastectomy [2]. Reconstructive surgery following mastectomy is also becoming more widely available and women who have had difficulty coming to terms with a mastectomy pursue this at the earliest opportunity.

Set against this background is the small proportion of young women who develop breast cancer where there is a known or suspected hereditary breast cancer predisposition gene. The outcome of treatment for breast cancer in this group is similar to that in an age matched population with no known cancer predisposition although reports have been mixed [7]. Reports suggesting an improved prognosis in BRCA1 gene carriers [6] are likely to reflect ascertainment biases as these studies were based on families identified for linkage studies. This usually requires a certain number of living affected individuals to be available for blood sampling. The histology of breast cancer in BRCA1 gene carriers is more often high grade and of medullary or atypical medullary type $[1,5]$ and hormone receptor negative [7].

For gene carriers the option of prophylactic mastectomy may be discussed although uptake is generally not high. The only published evidence of efficacy in reducing cancer risk is based on a retrospective review [4]. Uptake of this option is likely to depend on many factors including perception of risk, perception of screening efficacy, psychosexual and cultural differences.

In one recently published study [3] the effectiveness of treatment modality in young women with breast cancer was studied. 201 women affected by breast cancer under 35 years were included, only 29 of these had a family history of breast cancer. This small study concluded that breast conserving surgery and adjuvant radiotherapy gave similar levels of local control in both groups. In the family history positive group there was a higher incidence of contra-lateral breast cancer.

We have reviewed a much larger group of 305 patients from Southampton and Manchester. 142 had a definite (75 known BRCA1 gene carriers) or likely (56 early onset and 11 bilateral with a 
Table 1

Cumulative risk of future breast cancer in $\mathrm{FH}+$ and $\mathrm{FH}-$ patients

\begin{tabular}{lcccc}
\hline \multirow{2}{*}{ Interval since diagnosis } & \multicolumn{2}{l}{$\begin{array}{l}\text { Risk of contralateral breast cancer } \\
\text { (cases ascertained for bilaterality excluded) }\end{array}$} & Risk of ipsilateral recurrence (all cases) \\
\cline { 2 - 5 } & $\mathrm{FH}+$ & $1 \%$ & $\mathrm{FH}+$ & $\mathrm{FH}-$ \\
\hline 2 years & $6 \%$ & $3 \%$ & $1.5 \%$ & $9.5 \%$ \\
5 years & $17 \%$ & $12 \%$ & $15 \%$ \\
10 years & $35 \%$ & $7 \%$ & $20.5 \%$ & $20 \%$ \\
\hline
\end{tabular}

significant family history of breast cancer) genetic predisposition to breast cancer and were classified as $\mathrm{FH}+.163$ matched breast cancer cases had no family history of breast cancer and were classified as $\mathrm{FH}-$.

The median age of onset in the $\mathrm{FH}+$ group was 37 , mean 38.3 (24-75) and in the $\mathrm{FH}-$ group it was 38, mean 38.4 (19-67). There was no significant difference in tumour size (2.5 for $\mathrm{FH}+$ versus 2.6 for $\mathrm{FH}^{-}$) or axillary node status and in both groups there was a similar proportion who had been treated with breast conserving surgery rather than mastectomy. Adjuvant treatment was also similar in both groups. The pathology was recorded from the original notes (tumour pathology was not reviewed). There were significantly more medullary cancers in the $\mathrm{FH}+$ group ( 8 versus 3 ) and more in situ cancers (9 versus 3 ) in the $\mathrm{FH}-$ group. Ipsilateral recurrence, contralateral breast cancer and distant spread were examined in the two groups in addition to overall survival. The chance of an ipsilateral recurrence in the breast for those treated with breast conservation was 0.14 in the $\mathrm{FH}+$ group and 0.15 in the $\mathrm{FH}^{-}$group. In contrast there was a highly significant difference in the risk of contralateral breast cancer occurring for the $\mathrm{FH}+$ group compared to the $\mathrm{FH}-$ group $(p<0.001)$ regardless of treatment modality for the first primary. For $\mathrm{FH}+$ the cumulative probability of contralateral cancer at 10 years was 0.38 compared with 0.10 for the $\mathrm{FH}-$ group. There was no evidence for an excess of contralateral breast cancers in either the $\mathrm{FH}+$ group receiving adjuvant radiotherapy or those receiving adjuvant chemotherapy. However the follow-up time was relatively short to see any late effects of radiation from primary treatment if this were to increase the risk of ipsi- or contralateral new primaries. Overall survival was the same in both groups $(\mathrm{p}=0.19)$.

\section{CONCLUSIONS}

Breast conserving treatment in women genetically predisposed to breast cancer provides equivalent local control to that seen in women with sporadic breast cancer. However in discussing treatment choices the risk of cancer occurring in the contralateral breast must be made clear.

\section{References}

[1] Armes, J.E., Egan, A.J.M., Southey, M.C., Dite, G.S., McCredie, M.R.E., Hopper, J.L. and Venter, D.J. The histologic phenotypes of breast carcinoma occurring before age 40 years in women with and without BRCA1 and BRCA2 germline mutations. Cancer 83, (1998) 23352345.

[2] Boyages, J., Recht, A., Connolly, J., et al. Early breast cancer: predictors of breast cancer recurrence for patients treated with conservative surgery and radiotherapy. Radiother. Oncol. 19, (1990) 29-33.

[3] Chabner, E., Nixon, A., Gelman, R., Hetelekidis, S., Recht, A., Bornstein, B., Connolly, J., Schnitt, S., Silver, B., Manola, J., Harris, J. and Garber, J. Family history and treatment outcomes in young women after breast-conserving surgery and radiation therapy for early-stage breast cancer. $J$. Clin. Oncol. 16(6), (1998) 2045-2051.

[4] Hartmann, L.C., Schaid, D.J., Woods, J.E., Crotty, T.P., Myers, J.L., Arnold, P.G., Petty, 
P.M., Sellers, T.A., Johnson, J.L., McDonnell, S.K., Frost, M.H. and Jenkins, R.B. Efficacy of bilateral prophylactic mastectomy in women with a family history of breast cancer. New Eng. J. Med. 340(2), (1999) 77-84.

[5] Lakhani, S.R., Jacquemier, J., Sloane, J.P., Gusterson, B.A., Anderson, T.J., van de Vijver, M.J., et al. Multifactorial analysis of differences between sporadic breast cancers and cancers involving BRCA1 and BRCA2 mutations. J. Natl. Cancer Inst. 90, (1998) 1138-1145.

[6] Porter, D.E., Cohen, B.B., Wallace, M.R., Smyth, E., Chetty, U., Dixon, J.M., Steel, C.M. and
Carter, D.C. Breast cancer incidence, penetrance and survival in probable carriers of BRCA1 gene mutations in families linked to BRCA1 on chromosome 17q12-21. British Journal of Surgery 81, (1994) 1512-1515.

[7] Verhoog, L.C., Brekelmans, C.T.M., Seynaeve, C., van den Bosch, L.M.C., Dahmen, G., van Geel, A.N., Tilanus-Linthorst, M.M.A., Bartels, C.C.M., Wagner, A., van den Ouweland, A.M.W. and Devilee, P. Survival and tumour characteristics of breast cancer patients with germline mutations of BRCA1. Lancet 351, (1998) 316-332. 


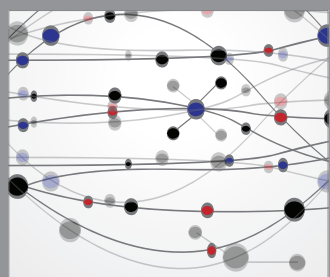

The Scientific World Journal
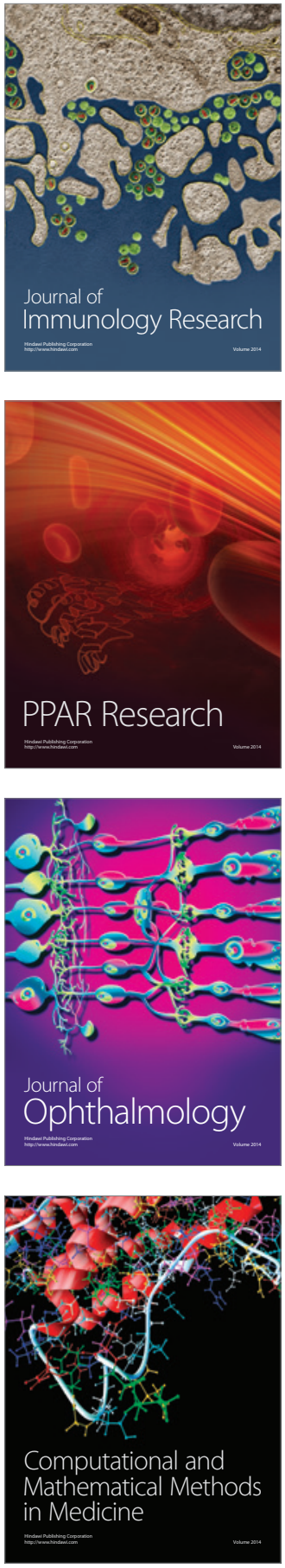

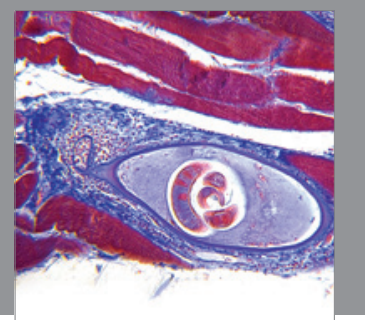

Gastroenterology

Research and Practice
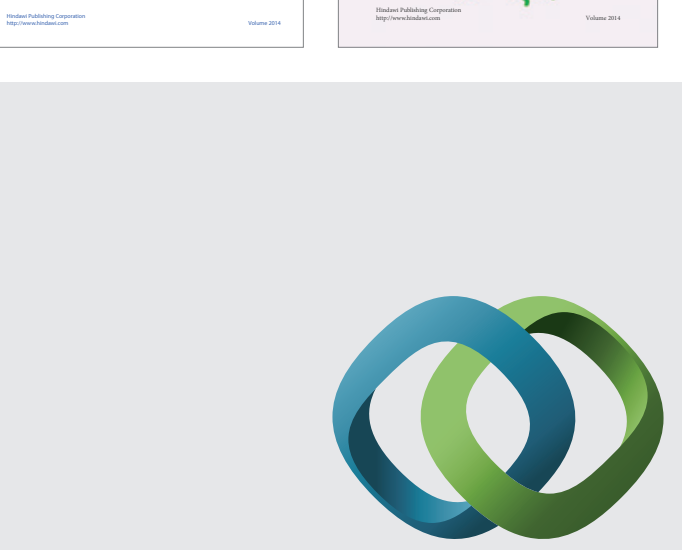

\section{Hindawi}

Submit your manuscripts at

http://www.hindawi.com
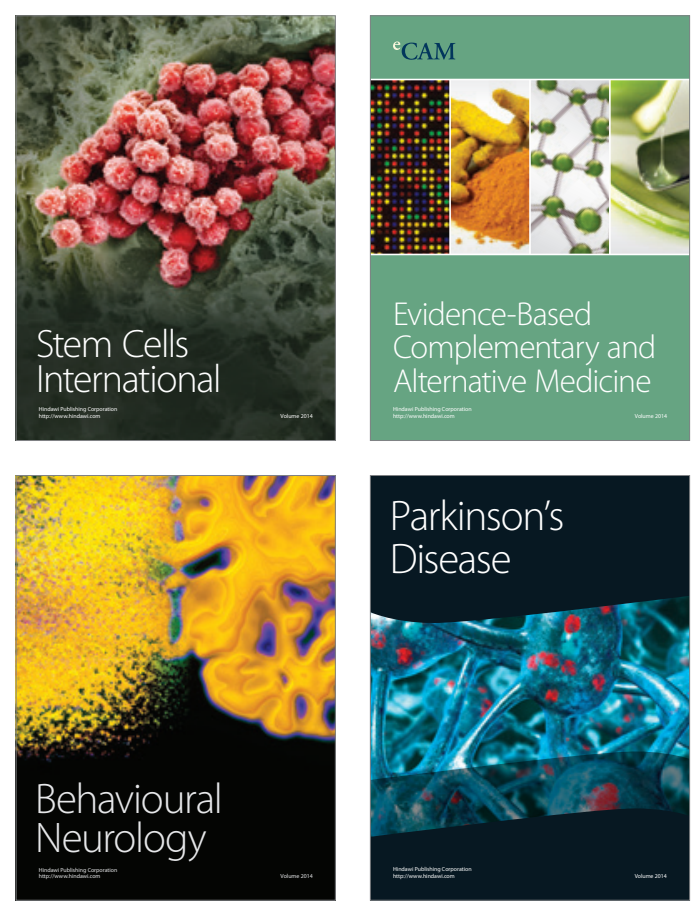

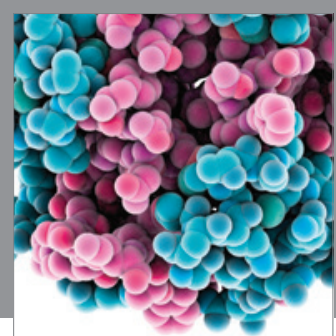

Journal of
Diabetes Research

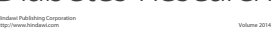

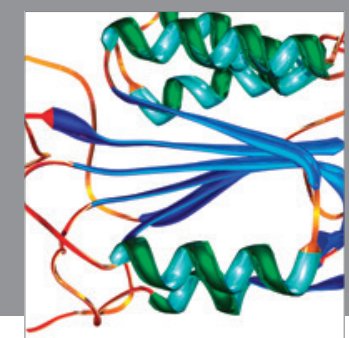

Disease Markers
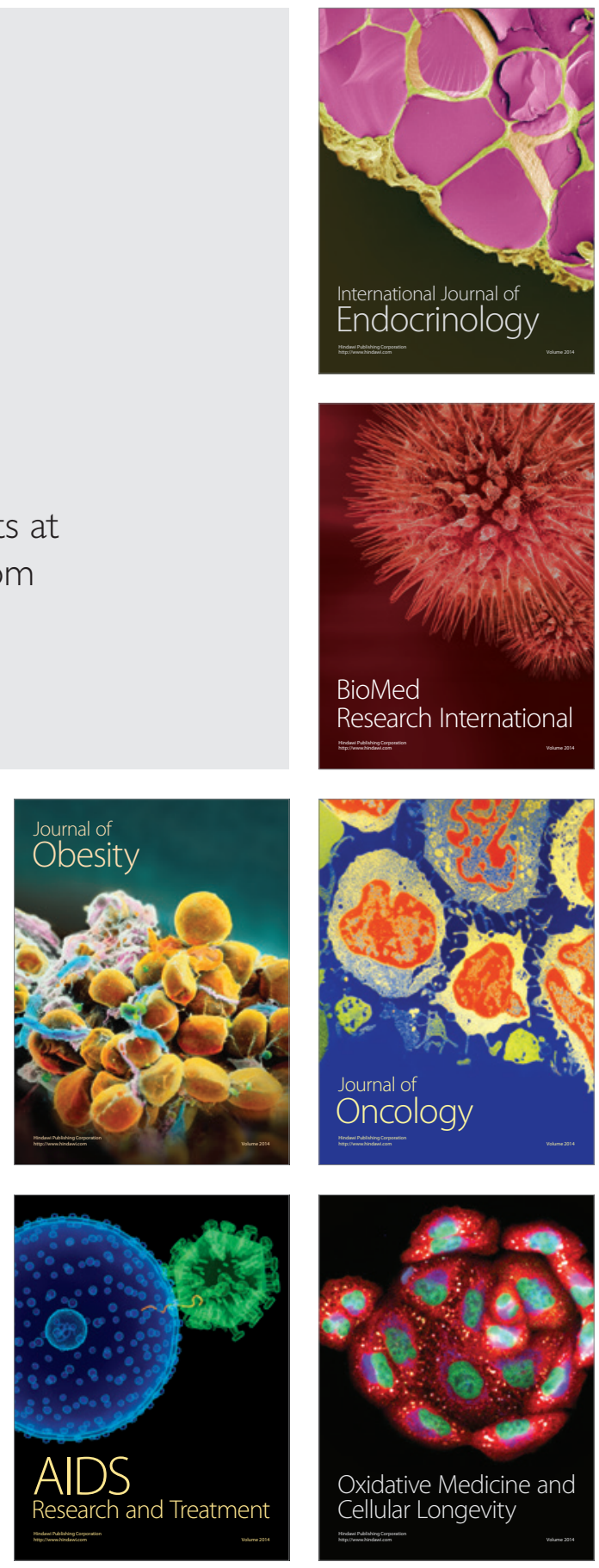